Global Co-Operation in the New Millennium

The 9th European Conference on Information Systems

Bled, Slovenia, June 27-29, 2001

\title{
KNOWLEDGE, LEARNING AND IT SUPPORT IN A SMALL SOFTWARE COMPANY
}

\author{
Karlheinz Kautz \\ Tel.: +45 3815 2400, Fax: +45 38152401 \\ Karl.Kautz@cbs.dk \\ Kim Thaysen \\ MINDPASS AS, Vardevej 1, DK-9220 Aalborg, Denmark \\ Tel.: +45 4473 3000, Fax: +45 44733001 \\ kth@mindpass.com
}

Copenhagen Business School, Department of Informatics, Howitzvej 60, DK-2000 Frederiksberg, Denmark

\begin{abstract}
The literature in the field of knowledge management shows a certain preoccupation with information technology (IT) and technical solutions while it reflects a limited view of organisational knowledge. The practice of knowledge management is commonly degraded to implementation of new IT based systems, neglecting important organisational aspects, in particular, human and social issues. This paper presents a case that involves a small Danish software company where these matters have been taken into account. The starting point for the utilisation of IT was a study of the concepts, knowledge and learning. Embedded in the daily activities of employees, IT, as just one of several measures, is intended to support and facilitate learning rather than regulate or impede the process. This will be demonstrated with two examples from the case. In this context, we will also examine to what extent it makes sense to distinguish between different types of knowledge and knowledge processes and how far different perspectives of knowledge management contribute to the deployment of appropriate IT support.
\end{abstract}

\section{INTRODUCTION}

In recent years, the concept of knowledge management has gained more and more attention from academics as well as practitioners. In this context, knowledge management is broadly understood as any process or practice of creating, acquiring, capturing, sharing and using knowledge wherever it resides to enhance learning and performance in organisations (Quintas et al., 1997).

However, as Swan et al. (1999) put forward, the literature published in the field shows a certain preoccupation with information technology (IT) and technical solutions while it reflects a limited view of organisational knowledge. The practice of knowledge management is commonly degraded to implementation of new IT based systems, neglecting important organisational aspects, in particular, human and social issues.

This paper presents the case of a small Danish software enterprise where these matters have been adequately taken into account. The starting point for the utilisation of IT was a study of the concepts knowledge and 
learning in an individual and an organisational context. The study set the stage and identified the conditions in which knowledge processes can take place. Embedded in the daily activities of employees, IT, as just one of several measures, is applied in order to support and facilitate learning rather than dictate, regulate or even worse obstruct the process. This will be demonstrated with two examples from the case.

In this context, we will also examine to what extent it makes sense to distinguish between different types of knowledge and different kinds of knowledge processes and how far the different perspectives and approaches complement or exclude each other.

Introducing knowledge management in the organisation was part of a large organisational change process that aimed at improving the organisation's software process (Kautz, \& Nielsen, 2000). This was originally organised as an action research project, which involves an approach that attempts simultaneously to achieve practical value for the client organisation and contribute to theoretical knowledge (Avison et al., 1999). A team of three researchers - two of whom are now full-time employees in the organisation - was on a varying scale actively involved in the process as change agents and mentors for the intended alterations. In addition to involvement in the project, observations, informal conversations, formal interviews, official meetings and document studies were part of the methods for collecting the data on which this article is based.

The article is structured as follows. In the next section, we will reflect in more detail on the concepts of knowledge and learning and present an argument for their relation to IT. Then, we will describe project planning, task management and quality assurance in terms of knowledge processes in addition to the actual utilisation of IT in the context of these processes in the case organisation. Finally, we will discuss the case based on the preceding descriptions and draw some conclusions with regard to knowledge management in organisations.

\section{KNOWLEDGE, LEARNING AND IT}

As stated earlier, we have recently seen a growing interest in the concept of knowledge and how knowledge can be captured and made the subject of IT. In this context, knowledge is quite often seen exclusively as a commodity like data or information (see e.g. Huber (1991) and Alavi \& Leidner (1999)). Such a perspective on knowledge is rather simplistic and might be one of the reasons why there are so few successful reports on knowledge management projects. Therefore, our study is based on the different views on knowledge and learning in the two philosophies of science, positivism and hermeneutics.

\subsection{Knowledge}

Dahlbom \& Mathiassen (1993) argue that from a positivistic perspective knowledge is rather like information. It can be collected and processed, and whether it includes facts or generalisations based on facts, it is an objective commodity that can be measured, bought and classified. It can be stored in people, in books or on hard disks.

They continue to argue that from a hermeneutic perspective knowledge is not a commodity, which can be collected under controlled conditions and bought or sold on a market. Knowledge is subjective enlightenment, a personal property. However, although it may be difficult, it is possible to share knowledge, provided there is a mutual respect and a sincere attempt at understanding.

The perspective that knowledge is embedded in and constructed from social relationships is put forward by e.g. Nonaka (1994). He argues that knowledge simply cannot be processed as information, because it is continuously re-created and re-constituted through dynamic, interactive social networking activity.

Knowledge is a complex, multifaceted concept. Following Polanyi (1966), Nonaka distinguishes between explicit, codifiable knowledge, which can be transmitted through formal, systematic language, and tacit knowledge, which is rooted in action and difficult to formalise and communicate. 
Drejer \& Henriksen (1998) present a further distinction of knowledge categories, which goes back to the Greek philosopher Aristotle. He classified theoretical - episteme - general knowledge, i.e. knowing that something is, as a type of knowledge that can be represented in the form of information as rules, procedures or standards. Practical - techne - knowledge deals with how something is done. It can be achieved through observation, studies and descriptions that contain information, but it is only considered knowledge when applied in practice. Social - phronesis - knowledge deals with a person's or a group's values, understanding of, and attitudes towards what to do and how to behave in certain, social environments. Such knowledge is communicated through stories and rituals. 1 The concepts of explicit and theoretical knowledge appear to be quite similar, just as those of tacit and practical knowledge do, while social knowledge seems to include both explicit and tacit elements.

The distinction between explicit and tacit and between theoretical and practical knowledge mirrors to a certain extent the distinction between positivism and hermeneutics. However, as theoretical knowledge is based on practical knowledge and vice versa, the concepts complement rather than oppose each other.

\subsection{Learning}

Similar to knowledge, learning is a complex phenomenon. With regard to organisational learning, Thoresen (1995) identifies two approaches in literature based on Cook \& Yanow (1993). One approach considers organisations as cognitive entities, the other understands them as communities-of practice. Again, both perspectives supplement each other. The latter concept suggests that even if knowledge is considered a personal property, the idea of learning as mere cognitive, decontextualised acquisition through individuals is inadequate when learning is seen in the context of people acting together (see e.g. Lave (1993) or Elkjaer (1999)). Learning is a social process that takes place in and through participation in communities-of-practice (Brown \& Duguid, 1991).

Huber (1991) who advocates the first perspective distinguishes knowledge acquisition, information distribution, information interpretation and organisational memory as processes and constructs that contribute to organisational learning, while Pentland (1995), based on Holzner \& Marx (1979) identifies what he calls knowledge processes, namely construction, organisation, storage, distribution, and application of knowledge which constitute organisational knowledge systems. Both frameworks are widely overlapping. In our analysis, we will therefore consider the processes of acquisition and construction, distribution and organisation, interpretation and application, and memory and storing together and take a closer look at their relationship to theoretical, practical, and social knowledge.

Theoretical knowledge is acquired by combining explicit knowledge from different sources. The underlying information can be distributed orally, by means of written texts or through other instruments, e.g. electronic media. The interpretation of the information depends on the individuals' prior mental frame of reference and in the case of an organisation on the uniformity of these cognitive maps (Huber, 1991). Theoretical knowledge is memorised and stored as scripts, routines or facts by humans or in the form of symbolic representations in external media as suggested above.

In the perspective of communities-of-practice, theoretical, formal knowledge as such does not exist. Practical and social knowledge is acquired through practical and social actions in networks of people. Such knowledge cannot just be distributed by speech or texts. Stories are told not just to convey mere knowledge, but to learn to speak a community's language. Distribution and sharing of knowledge take place through participation and/or apprenticeship in the communities-of-practice. As the embodied ability to behave and act as a member of a community, knowledge is profoundly connected to the conditions under which it is learned and stored. Interpretation is framed by the communal context and therefore it is to a large extent not explicit or

1 Aristotle also described a fourth category of knowledge: knowledge about myth - metis knowledge - which we, however, will not consider here. 
explicable (Brown \& Duguid, 1991). Information on how to do things and how to behave may be stored in manuals, stories or as guidelines, but it only becomes knowledge when it is practised.

Nonaka (1994) does not employ a distinction between acquisition, distribution, interpretation and storage. He focuses on what he calls the organisational knowledge creation process and distinguishes between four modes of knowledge creation based on his theory, which argues that knowledge is created by converting explicit knowledge and tacit knowledge. The conversion takes place in an interactive social process through continuous communication and involves different individuals, groups and organisational units.

To support the combination of explicit knowledge items, he proposes written documentation and traditional meetings. Beyond this, learning-by-doing is seen as a means to internalise explicit knowledge as tacit knowledge. Continuous dialogue and the use of metaphors are especially proposed as a means to externalise tacit knowledge as explicit knowledge, and finally master-apprentice relationships and team work are suggested as a means to socialise tacit knowledge.

Nonaka postulates that the organisation provides the context in which individuals create knowledge. He argues that knowledge creation is supported in an environment where individuals show an intention and have the autonomy to create knowledge. Individuals should be allowed to act in a milieu characterised by fluctuation and variety and where change and deviations from routine performance, including breakdowns in the daily practice, are acknowledged as an opportunity and not considered a problem. This idea is supported by Argyris \& Schön (1996) who argue that individuals can learn in organisations when they are confronted with uncertain and problematic situations. To support knowledge creation, Nonaka also proposes selforganising and cross-functional teams, just as he emphasises the role of mutual trust and redundant information and advocates a management style, in which leaders act as catalysts in team-oriented organisations.

\subsection{IT Support}

There are obviously differences between the various views on knowledge and learning in the context of organisations. We have identified a more individually based and a more communally based approach. However, we consider the different perspectives to be complementary. This view allows us to draw the following conclusions about IT support for knowledge management.

IT may provide direct assistance for acquisition, distribution and storage of information as a basis for theoretical knowledge, but the interpretation of such information is a human activity that cannot be assisted directly. In terms of practical and social knowledge, IT can only, if at all, assist implicitly in providing information to support the processes and circumstances that enable knowledge creation and knowledge management.

We will now use the established framework to present and discuss the concrete case of learning and knowledge utilisation in a small Danish software enterprise.

\section{A CASE OF UTILISING KNOWLEDGE}

The company NP is developing an IT-based solution to the problem of how to present 20000 warehouse items on a 14" screen through a slow network in a fast and structured way. A focus on knowledge and learning began to emerge during a software process improvement (SPI) initiative that aimed at improving the company's business and development processes. The implementation of SPI in NP included supplying SPI knowledge from the outside (Kautz \& Nielsen, 2000) and performing the first SPI activities. The improvement project is still going on and is the subject of a longitudinal study. Here, we are concerned with the knowledge processes in relation to the first improvement activities.

The company was founded in 1997 by two persons with a business and an IT background, respectively. From the start of the improvement project in early 1998, the number of employees has grown from 25 to well over 60 in mid 1999. Most of the staff is directly involved in software development and the rest in business 
administration, marketing and sales. The two founders function as management. Software development is roughly divided into two divisions. A production division delivers standard intra- and internet solutions. Besides software developers, the division consists of an operational - network administration - staff and art designers. The other part of the organisation's operation takes place in the growing research and development division. It deals with the future product of the organisation. It is this division that is the focus of our study.

The work in this division is rather project and teamwork-oriented. Three overall project groups are managed by three project leaders who function as co-ordinators for a varying number of subprojects where the employees, in groups of $4-5$ persons, perform all sorts of development tasks. Often, there are no strict boundaries between the subprojects, and the project groups only exist for a short period of time until the problem that led to their establishment has been solved. To solve the problems will normally involve members, especially art designers, from the production group and other subprojects. In addition, there is a general project co-ordinator who keeps track of the different activities and together with the three project leaders form a so-called steering group.

NP is characterised by an entrepreneurial and frank atmosphere. There is a high degree of internal communication and social interaction, also outside office hours, and mutual adjustment is used as the primary co-ordination mechanism. Employees trust each other and show mutual respect for each other's capabilities. As a project-oriented organisation, NP is geared by and towards innovation, and a creative, dynamic, energetic and at times hectic atmosphere prevails. All employees are placed in an open office landscape, and NP largely employs young, newly graduated and highly educated people who have a background in information systems, computer science or organisational science and are open to newfangled ideas.

Management takes the strategic decisions on business and products. Their management style is managementby-walking-around. Management expects everyone to assume responsibility and work for a common interest. The project managers maintain an overview of the technical tasks and achievements. The software developers enjoy a fair amount of autonomy, which extends to the solutions of technical problems as well as the purchase of tools and other materials. They have the opportunity to specialise within their fields of interest and are in many respects free to determine which tasks they would like to concentrate on and which problems they would like to solve. They are enthusiastic about their work, and long working hours, although not necessarily appreciated, are just one sign indicating their commitment and motivation.

\subsection{Project Planning and Task Management as Knowledge Processes}

In a dynamic environment, new opportunities and challenges to improve the product constantly emerge, giving rise to frequent changes in requirements. Therefore, project planning and change, or rather task management in the case of NP, play an important role.

Often, the organisation was confronted with a situation where project plans, especially time schedules, had not been produced, which made project tracking nearly impossible. Lists of amendments, if any, were not made and updated on a regular basis to the effect that there was no overview of ongoing and new tasks. Tasks were seldom estimated, and their impact on the project as a whole was rarely assessed. Finally, project members had no general knowledge about the status of their colleagues' work and often no clear perspective of their own work. The company tried to use a widely accepted project planning tool, which, however, only supported traditional projects where sequential performance of tasks can be planned and monitored, but where all information is related to fixed deadlines without any chance of documenting and learning from project history. Thus, there was a need for better planning in addition to tracking and co-ordination of the project as a whole, including the subprojects involved.

As a consequence, NP established two working groups comprising nearly all staff members. They developed an understanding of project planning and task management as knowledge and learning processes - an outcome of the earlier mentioned study of these concepts - and analysed and restructured their routines. 
Furthermore, the two members who were assigned full-time to improvement activities developed an accompanying IT based tool.

Knowledge construction in relation to product amendments is generated through market research and uptake of new research results, including product ideas that emerge from the daily practice. This process is implicitly supported by IT as the Internet is surfed for interesting information, but this is not the kind of IT support we will consider here. Everyone in the organisation is involved in this type of knowledge construction, but it is the steering group who has the overall responsibility for managing new requirements and tasks. Before the steering group or a project leader approves new ideas, they are stored and distributed to all interested and affected employees through an IT-based list of ideas. A crucial role in the process is played by co-ordination meetings where the steering group or parts of it and the respective developers evaluate and interpret the information available and decide whether to continue to explore and follow up on an idea or a new requirement. In this process, an experienced developer makes a rough estimate of the resulting task, and often a preliminary risk analysis will be performed, which in turn also involves an interpretation process. If the proposals are approved, the tasks will be subdivided and distributed.

Upon approval, an idea becomes a task, and the developers who volunteered or were assigned to the job transfer the idea description to their own planning tools. From now on, the individual developers, who constitute a small subproject, are by and large responsible for detailed planning, tracking and overview. In general, the developers perform their tasks individually, but with assistance from colleagues, if necessary. Only once a week, does the project leader, one of the three overall project managers in whose area the subproject falls, produce a status report from the information provided by the developers, and, if necessary, he will eventually take action. In the organisation, this process is called participative project management.

As part of their daily work, the developers describe their subtasks based on their shared knowledge from the co-ordination meeting. They start by outlining their perception of the co-ordination meeting, explaining the background of the tasks and their decisions and classifying the tasks according to a simple scheme. Using a rudimentary method, the developers estimate their subtasks according to a best case, worse case and the most likely scenario in terms of calendar days and working hours. They also describe the risk and finally provide a list of all other developers involved in or affected by their actions. This can be regarded as part of knowledge construction and stored in the IT-based tool. During task performance, the developers will update the information regularly. The information is accessible to everyone while there is constant communication within the project group and beyond about the issue at hand. The information as interpreted by the different developers and the project leaders is used for co-ordination purposes on an informal day-to-day basis and on more formal status and co-ordination meetings.

The tool only supports distribution and storage of information to enable everyone to get an overview of the status of their own tasks, the status of others' tasks, the relation between these and the status of the project as a whole. In addition, it is used for resource tracking based on estimates and actual progress, thus supporting re-planing.

Interpretation of information is the key issue. The fact that a specific coding task at a certain point in time had overrun its estimate by $400 \%$ was interpreted as a case of inexperienced estimation and adjusted accordingly. The problem that an analysis task had overrun its estimate by $160 \%$ was resolved by means of the task description, which indicated that several subtasks had emerged during performance and required further manpower. Furthermore, comparing estimates based on working hours and estimates based on calendar days uncovered certain planning deficiencies. Some tasks had overrun their deadline, yet there were still working hours available. Others had used all their working hours, yet the deadline had not been reached. We may view all the actions involved, namely readjustment of plans and estimates, and the reassignment of staff as a result of knowledge based on practice, developed in communities-of-practice and of practical knowledge, knowledge of how to do things. It is also important to note that the information was not used to blame individuals, but to improve the process. The knowledge about the social norms in the organisation, namely an appreciation of openness and honesty based on mutual trust rather than concealment of information and mistrust, supported and reinforced this practice. 
The introduction of co-ordination meetings had various effects: They supported the sharing of knowledge and encouraged to engage in individual and collective reflection. This communal process strengthened the mutual commitment to fulfil accepted tasks. The developers also reported that - although the IT support was quite basic - access to information, as a basis for the other knowledge processes, had been extremely simplified and improved. Estimations - now available as stored numbers with additional descriptions - had been practised and their accuracy had increased. As a consequence, the co-ordination meetings had led to better, more precise, individual and communal planning. All employees welcomed the enhanced professionalism.

In terms of project planning and task management as knowledge creation processes, we may interpret the lists of ideas and task descriptions with information about the actual course of a project as combining explicit knowledge. The explicit knowledge is internalised when used in practice to amend plans and actions. It is externalised through the continuous dialogue between employees about the planning practice, which takes place in an open atmosphere and environment where - although tasks are generally performed individually joint planing in the form of participative project management prevails. This process can be seen as socialisation.

\subsection{Quality Assurance as a Knowledge Process}

Securing the quality of a software product has traditionally been done through testing. However, testing is also an activity, in which we can learn much about the quality of a product, its building process and improvements, if any. NP has implemented new test routines and a simple, accompanying IT-based tool to support detection and analysis of errors and deficiencies in their software products.

The usual test procedures will uncover errors, but with the new routines they are also classified according to a basic classification scheme and comprehensively documented and reported with the help of an elementary report template.

The classification has been decided in common and distinguishes between e.g. graphical user interface errors, semantic errors, exception handling errors and uncorrected errors from previous tests.

The report template is divided into two parts. One part contains a short description of the error, its location, its significance and an identification of the responsible developer. In the second part, a short description of a possible solution and the effort required can be made.

In this respect, knowledge construction involves testing itself, the production and provision of the resulting descriptions and information in addition to measurements of the different types and sources of errors, which are produced during or after testing sessions by individual testers or a group especially assigned to the task. The descriptions and measurements are distributed as information - at best theoretical knowledge - in the form of reports and graphs, which makes the information visible and accessible to everyone in the organisation. Test reports are not only distributed electronically, but also prominently exposed on the walls of a meeting room. They are also stored in the same way. Interpretation and application is only implicitly supported by IT - the tool is only used to collect information. Subsequently, developers and project leaders will interpret as individuals and in common what is at their disposal.

The fact that at a certain point in time a fifth of all errors were user interface errors - a fact which first became apparent to everyone by means of the tool - was interpreted as a lack of knowledge in this particular area. It resulted in additional training for the employees and in the employment of user interface specialists as additional staff members. It was only through use that theoretical knowledge became practical knowledge. Another example deals with uncorrected errors. In one case, it turned out that from one test run to the next only a fourth of the detected errors had been corrected. The project leaders but also the staff itself were interested in discovering who had failed to correct their errors and why. The information was used to reflect upon practice and interpreted by project management, the projects and the developers as a sign of work overload. As a consequence, both development and testing were re-planned and restructured and became part 
of the improved project planning routines. The only role IT support played in this connection was to provide easy access to information visualising the facts.

The information also had another effect. The developers interpreted the information as part of a competition where the aim was to correct as many errors as possible. While such a competition might have let to a stressful peer pressure in many environments, it was not in conflict with the existing social environment here. The same thing happened with the information about who had originally been responsible for an error. Again, after the staff had planned to provide a better overview and basis for planning, competition started and the individual developers produced fewer errors before the common testing. However, such a course of events may only be possible because the staff itself is interested in the information to improve the process, and they do not use the information to scapegoat other colleagues. The social knowledge shared by all employees makes it possible to deal with very sensitive data.

If quality assurance is viewed as a knowledge creation process, we may consider the use of reports, classification schemes and measurements as a means to combine explicit knowledge. The knowledge is subsequently internalised through application in practice by changing work routines and externalised through continuous dialogue in a co-operative environment and by communal testing practice. Through this process, knowledge is also socialised.

\section{DISCUSSION AND CONCLUSION}

The introduction of IT in organisations to support human practices is a complex phenomenon that has been the subject of research in a number of years. In this paper, we will refrain from discussing implementation of IT in more general terms and concentrate on knowledge processes and how they can be supported through IT.

In our study, we have used a framework that distinguishes different models of knowledge and learning, different types of knowledge and different knowledge and learning processes. For presentation and analytical reasons, the distinction of theoretical, practical, social, explicit, tacit, as well as individual and collective knowledge has been very helpful. The same applies to seeing learning as an individual cognitive process or as a process that takes place in communities-of-practice. In terms of the actual construction and use of IT support, the distinction appears less helpful. The case has demonstrated how interrelated the different types of knowledge are and showed the close relationship between learning as an individual and as a collective process. The same is valid for the distinction of knowledge processes in acquisition/construction, distribution/organisation, storage/memory and interpretation/application, just as it applies to the concepts of socialisation, externalisation, internalisation and combination. The concepts are closely intertwined and to consider at least the first four as distinct processes might separate them from the social structures in which they are embedded.

This is where the real value of investigating the concepts of knowledge and learning lies in terms of providing adequate IT support. It has broadened the view of knowledge and shown that knowledge is more than an objective codifiable commodity. It has emphasised that learning takes place as and in a social practice, regardless of whether knowledge is individual, situated in a social context, or, collective and carried by the relations and interactions of the community members in a social situation. Knowledge might be individual, but it is socially constructed. To enable learning to take place, both the individual and the social structures have to be supported. In NP, there were openness, trust and mutual respect, and a commitment to its constituting elements intention, autonomy and fluctuation, to use Nonaka's terms (Nonaka, 1994), was promoted to support an environment in which knowledge processes could take place.

Other characteristics of the organisation were continuous dialogue and involvement, which were encouraged through physical structures like the office landscape and organisational measures such as regular coordination meetings that went beyond mere status reporting. Participative project management and a management style that favoured a close contact with the employees contributed to the milieu. 
Fitted into such a setting, IT played an important, yet subordinate role. The awareness that the social nature of knowledge gets lost in information processing (Pentland, 1995) has led to the insight that IT should only be used to gather, store and distribute information, leaving all other aspects of learning and knowledge to the human actors. This approach did not distract the attention from focusing on how to achieve knowledge, namely the process of learning. Even unforeseen effects like the competitions among the employees supported rather than impeded the learning processes.

As such, the case has demonstrated how a fairly simple IT-based tool can support learning processes in an organisation that understands knowledge and learning as something which goes beyond the mere transmission of codifiable facts.

The framework that we have used here has proved useful in presenting and analysing the case. However, in terms of construction and use of IT, its greatest merit lies in broadening the view of knowledge and learning as socially constructed phenomena.

\section{REFERENCES}

Alavi, M., D. Leidner (1999), Knowledge Management Systems: Issues, Challenges, and Benefits, Communications of the AIS, Vol. 1, paper 5, pp. 1-35

Argyris, C., D. Schön (1996), Organisational Learning II, Addison Wesley, Reading, MA, USA

Avison, D., F. Lau, M. D. Myers, P. A. Nielsen, (1999). Action research, Communications of the ACM, Vol. 42, No. 1, pp. 94-97

Brown, J. S., P. Duguid (1991), Organisational Learning and Communities-of-Practice: Toward a Unified View of Working, Learning, and Innovation, Organisation Science, Vol. 2, No. 1, pp. 40-57

Cook, S. D. N. \& Yanow, D. (1993) Culture and Organizational Learning, Journal of Management Inquiry 2(4): 373-390.

Dahlbom, B., L. Mathiassen (1993), Computers in Context - The Philosophy and Practice of Systems Design, Blackwell, Cambridge, UK

Drejer, A., L. B. Henriksen (1998), Views on Knowledge - From Aristotle to Senge, in Proceedings of the 13th Industrial Research Center Research Seminar, Design for Integration in Manufacturing, Fugls $\emptyset$, Denmark, April 20-21, 1998

Elkjaer, B. (1999), 'In search of a social learning theory', in M. Easterby-Smith, L. Araujo, J. Burgoyne (eds.), Organisational Learning and the Learning Organisation, Developments in Theory and Practice, Sage, London, UK, pp.75-91

Holzner, B., J. Marx (1979), Knowledge Application: The knowledge system in society, Ally-Bacon, Boston, MA, USA

Huber, G. P. (1991), Organisational Learning: The contributing Processes and the Literatures, Organisation Science, Vol. 2, No. 1, pp. 88-115

Kautz, K., P. A. Nielsen (2000), Introducing Software Process Improvement: Two Cases of Technology Transfer, in Proceedings of the Hawaii International Conference on System Sciences (HICCS-33) 2000, Maui, USA, January 4-7, 2000

Lave, J. (1993), The practice of Learning, in S. Chaiklin, J. Lave (eds.), Understanding Practice Perspectives on activity and context, Cambridge University Press, Cambridge UK, pp. 3- 32

Nonaka, I. (1994), A Dynamic Theory of Organizational Knowledge Creation, Organisation Science, Vol. 5, No. 1, pp. 14-37

Nonaka, I, H. Takeuchi (1995), The Konwledge-Creating Company, Oxford University Press, Oxford, UK 
Pentland, B. T. (1995), Information Systems and Organisational Learning: The Social Epistemology of Organisational Knowledge Systems, Accounting, Management \& Information Technology, Vol. 5, No.1, pp.1-21

Polanyi, M. (1966), The Tacit Dimension, Routlegde \& Kegan Paul, London, UK

Quintas, P., P. Lefrere, G. Jones (1997), Knowledge Management: A strategic agenda, Long Range Planning, Vol. 30, No. 3, pp. 385-391

Swan, J., H. Scarbrough, J. Preston (1999), Knowledge Management - The Next Fad to Forget People, in Pries-Heje, J. et al. (eds.) Proceedings of the 7th European Conference on Information Systems, Vol. I-II, June 23-25, 1999, Copenhagen, Denmark, pp. 668-678

Thoresen, K. (1995), Learning at work, in Kautz, K., J. Pries-Heje (eds.), Diffusion and Adoption of Information Technology, Chapman \& Hall , London, UK, pp. 176-201 